Pontifícia Universidade Católica $_{\text {ma }}$

Renato da Silva Machado

\author{
O Evangelho Trinitário para o \\ ser humano hoje \\ Cristologia e Trindade em Bruno Forte
}

Tese de Doutorado

Tese apresentada como requisito parcial para a obtenção do grau de Doutor pelo Programa de Pós-graduação em Teologia do Departamento de Teologia do Centro de Teologia e Ciências Humanas da PUC-Rio.

Orientador: Prof. Paulo Cezar Costa

Rio de Janeiro Março de 2015 


\title{
O Evangelho Trinitário para o ser humano hoje Cristologia e Trindade em Bruno Forte
}

\begin{abstract}
Tese apresentada como requisito parcial para a obtenção do grau de Doutor pelo Programa de Pós-graduação em Teologia do Departamento de Teologia do Centro de Teologia e Ciências Humanas da PUC-Rio. Aprovada pela Comissão Examinadora abaixo assinada.
\end{abstract}

\section{Prof. Paulo Cezar Costa}

Orientador

Departamento de Teologia - PUC-Rio

Prof. Luiz Fernando Ribeiro Santana

Departamento de Teologia - PUC-Rio

Prof. Maria Clara Luccheti Bingemer Departamento de Teologia - PUC-Rio

Prof. Dorival Souza Barreto Júnior UNIMONTES

Prof. Antonio Ascione

PFTIM

Prof. Denise Berruezo Portinari Coordenadora Setorial de Pós-Graduação e Pesquisa do Centro de Teologia e Ciências Humanas - PUC-Rio

Rio de Janeiro, 05 de Março de 2015. 
Todos os direitos reservados. É proibida a reprodução total ou parcial do trabalho sem autorização do autor, do orientador e da universidade.

\section{Renato da Silva Machado}

Possui mestrado em Teologia Sistemático-Pastoral com especificidade em Cristologia pela PUC-RJ; doutorando na mesma Universidade. Possui ampla atuação na pastoral eclesial com ênfase na liturgia e iniciação cristã. Atuou em cursos de teologia para leigos nas dioceses do Rio de Janeiro, Nova Iguaçu e Duque de Caxias lecionando principalmente disciplinas de teologia sistemática. Possui diversos artigos seja em revistas eletrônicas e convencionais. Presbítero, exerce atualmente o seu ministério na Basílica Imaculada Conceição Botafogo- Arquidiocese de São Sebastião do Rio de Janeiro.

Ficha Catalográfica

Machado, Renato da Silva

O Evangelho Trinitário para o ser humano hoje: Cristologia e Trindade em Bruno Forte/ Renato da Silva Machado; orientador: Dr. Paulo Cezar Costa. - Rio de Janeiro: PUC, Departamento de Teologia, 2015.

v., 359f: il. ; $29 \mathrm{~cm}$

1. Tese (doutorado) - Pontifícia Universidade Católica do Rio de Janeiro, Departamento de Teologia

Inclui referências bibliográficas.

1. Teologia - Teses; 2. Cristologia. 3. Trindade. 4. Bruno Forte. 5. Jesus Cristo. 6. Nova Evangelização. 7. História. I. Costa, Paulo C. (Paulo Cezar). II. Pontifícia Universidade Católica do Rio de Janeiro. Departamento de Teologia. III. Título. 

e transmitiram esta experiência no decorrer dos séculos. 


\section{Agradecimentos}

A Dom Bruno Forte, Arcebispo de Chieti-Vasto, pela disponibilidade, contribuição e amizade que foi construída ao longo desta pesquisa.

Ao Cardeal do Rio de Janeiro, Dom Orani João Tempesta, e ao Cardeal de Nápoles, Dom Crescenzio Sepe, que me acolheram em suas dioceses para o doutoramento.

A Dom Waldemar Chaves de Araújo, bispo emérito de São João del Rey, a Dom José Pinheiro e ao Mons. Pedro Diniz, pela graça do sacerdócio ministerial a mim conferida.

Ao Prof. Dr. Dom Paulo Cezar Costa, pelo estímulo e orientação na elaboração deste trabalho.

Ao CNPq, à CAPES e à PUC-Rio, pelo apoio financeiro sem o qual este trabalho não poderia ter sido realizado.

À Pontificia Facoltà dell'Italia Meridionale - Seção Santo Tomás, na pessoa de Pe. Antonio Ascione, que me possibilitou a pesquisa no exterior.

Aos prezados Pe. Jorge André, Côn. Joel Portella Amado, Pe. Marcos André Menezes dos Santos, Pe. Marcos Antônio de Santana, Mons. Raffaele Ponte, Pe. Antonio Colamarino e Côn. Marcos Willian Bernardo, com os quais tive a oportunidade de conviver nestes últimos anos.

Aos meus pais, Cleber Menezes Machado e Marlene da Silva Machado, e aos meus irmãos, Flávio, Maria Claudia e Patrícia, pelo ambiente de amor e carinho no qual cresci.

Ao Pe. Severino Alessio, meu pároco e reitor, que para mim é exemplo de santidade e foi o grande incentivador para meu ingresso na Pós-graduação.

Aos demais professores e amigos Pe. Mario de França Miranda, Leonardo Ribas e Carlos Frederico Schlaepfer, pelo companheirismo e incentivo na realização deste trabalho. 
À Vera Regina Polillo, pela ajuda valiosa, incentivo e amizade.

Aos amigos Antonio Marino, Sra. Adriana Bidelo, Sr. Vittorio Sparavigna, Sra. Agnese, Elisabeth Regina, pelo auxílio com a língua italiana e inglesa.

Aos amigos Mons. Jorge Azis, Mons. Jan Kaleta, Pe. Marcos Talon de Oliveira, Pe. José Antônio e Pe. Mario Fioravanti (in memorian), pelo auxílio e palavras de incentivo.

A todos os amigos e familiares que, de alguma forma, me ajudaram ou me estimularam.

Aos professores que compõem a banca, pela disponibilidade e testemunho de vida cristã.

A todos os professores, funcionários e amigos do Departamento de Teologia da PUC-Rio e da Pontificia Facoltà dell'Italia Meridionale, pelas importantes contribuições.

A todos os irmãos das paróquias Santa Rita de Cássia em Caieiras (SP), N. Sra da Conceição Aparecida no Cachambi (RJ), N. Sra. da Vitória na Barra da Tijuca (RJ), S. Maria di Costantinopoli em Nápoles (Itália), Imaculada Conceição em Botafogo (RJ), nas quais servi com amor na condição de presbítero.

À Diocese de Duque de Caxias na pessoa de seu primeiro bispo Dom Mauro Morelli e do atual, Dom Tarcísio Nascentes, por minha formação filosófica e teológica.

À minha querida e histórica paróquia de origem, Santa Terezinha do Menino Jesus no Parque Lafaiete (DC), na qual me apaixonei por Cristo e resolvi abraçar o sacerdócio ministerial.

Às comunidades e paróquias nas quais fiz estágio como seminarista: Com. N. Sra. do Rosário (DC), Com. N. Sra. da Esperança (DC), Com. N. Sra. da Conceição (SJ), Par. São Francisco (DC), Par. N. Sra. das Graças (DC).

Às Irmãs da Divina Vontade, Irmãs Vicentinas e demais Congregações e Movimentos com os quais tive a oportunidade de me relacionar.

À Igreja, Una, Santa, Católica e Apostólica, através da qual conheci e me apaixonei por Jesus Cristo. 


\section{Resumo}

Machado, Renato da Silva; Costa, Paulo Cezar. O Evangelho Trinitário para o ser humano hoje: Cristologia e Trindade em Bruno Forte. Rio de Janeiro, 359p. Tese de Doutorado - Departamento de Teologia, Pontifícia Universidade Católica do Rio de Janeiro.

A fé cristã se pauta, desde sua origem, na experiência de Deus Trindade - Pai, Filho e Espírito Santo - que se revela em Jesus Cristo, sobretudo em seu mistério pascal. Diante da atual crise de fé, os cristãos são incitados a promover uma Nova Evangelização, anunciando, com coragem e alegria, o Deus de Jesus Cristo como possibilidade de realização e salvação para o ser humano. Destarte, este trabalho objetiva apresentar, de modo sistemático, a cristologia trinitária de Bruno Forte como caminho para elaboração de um discurso sobre Deus que, partindo da Revelação Trinitária em Jesus Cristo, sobretudo no seu mistério pascal, supere as inúmeras deturpações e manipulações da imagem de Deus presentes no mundo hodierno que favorecem o ateísmo e o indiferentismo à questão de Deus. Procurar-se-á mostrar que uma cristologia trinitária poderá contribuir eficazmente para o caminho de conversão e de Nova Evangelização a ser assumido pela Igreja - esta a relevância do presente trabalho.

\section{Palavras-chave}

Trindade; Cristologia; Jesus Cristo; Nova Evangelização; Bruno Forte. 


\section{Abstract}

Machado, Renato da Silva; Costa, Paulo Cezar (Advisor). The Trinity Gospel for the human being today: Christology and the Trinity in Bruno Forte. Rio de Janeiro, 359p. Doctoral Thesis - Departamento de Teologia, Pontifícia Universidade Católica do Rio de Janeiro.

The Christian faith is based from its origin in the Trinity experience of God Father, Son and Holy Spirit - which is revealed in Jesus Christ, especially in his paschal mystery. Before the current faith crisis, Christians are encouraged to promote a New Evangelization announcing, with courage and joy, the God of Jesus Christ as a possibility of fulfillment and salvation. This thesis work aims to present, in a systematic way, Bruno Forte's Trinitarian Christology as a way to prepare a discourse about God which, from the Trinitarian revelation in Jesus Christ perspective, especially within the scope of his paschal mystery, will overcome the numerous misinterpretations and manipulations of God's image which have been promoting atheism and indifference to the question of God. It will show that a Trinitarian Christology can contribute effectively to the path of conversion and new evangelization to be assumed by the Church.

\section{Keywords}

Trinity; Christology; Jesus Christ; New Evangelization; Bruno Forte. 


\section{Astratto}

Machado, Renato da Silva; Costa, Paulo Cezar (direttore di tesi). Il Vangelo Trinitario per l'uomo di oggi: la Cristologia e la Trinità in Bruno Forte. Rio de Janeiro, 359p. Tesi di dottorato - Departamento de Teologia, Pontifícia Universidade Católica do Rio de Janeiro.

La fede cristiana si fonda nella sua origine nell'esperienza di Dio TrinitàPadre, Figlio e Spirito Santo - che si rivela in Gesù Cristo, in particolare nel suo mistero pasquale. Data l'attuale crisi della fede, i cristiani sono invitati a promuovere una nuova evangelizzazione, annunciando con coraggio e gioia, il Dio di Gesù Cristo come possibilità di salvezza per l'essere umano. Questo lavoro, pertanto, presenta in modo sistematico, la cristologia trinitaria di Bruno Forte come un cammino per elaborare un discorso su Dio, che partendo dalla rivelazione trinitaria in Gesù Cristo, e in modo alquanto unico nel suo mistero pasquale, supera le numerose deturpazioni e manipolazioni dell'immagine di Dio presenti nel mondo di oggi, che promuovono l'ateismo e l'indifferenza alla questione di Dio. Si proverà a dimostrare come una cristologia trinitaria possa contribuire efficacemente al cammino di conversione e nuova evangelizzazione ed essere assunta dalla Chiesa - questa la rilevanza del presente lavoro.

\section{Parole chiave}

Trinità; Cristologia; Gesù Cristo; Nuova Evangelizzazione; Bruno Forte. 


\section{Sumário}

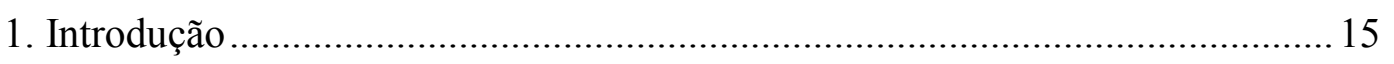

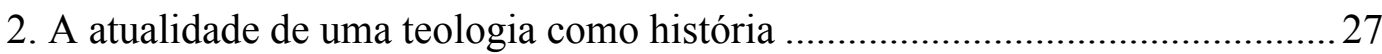

2.1 A consciência histórica do presente: os questionamentos da história à

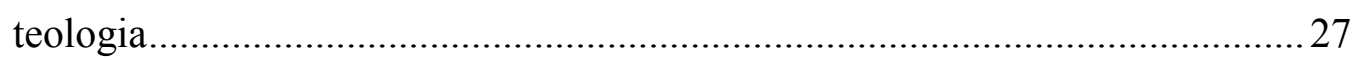

2.2 O significado da revelação trinitária para hoje .......................................... 35

2.3 A Teologia como consciência crítica da experiência trinitária .................... 45

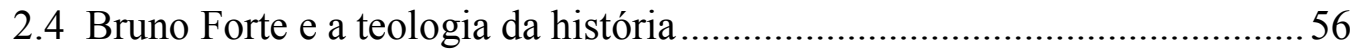

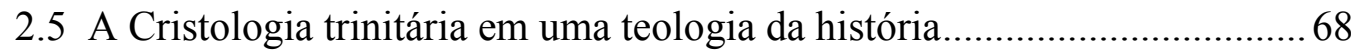

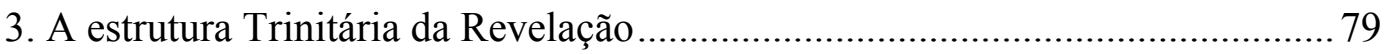

3.1 Evento Pascal, lugar da fé trinitária e conteúdo da revelação..................... 80

3.2 As tríades da estrutura formal do pensamento sobre a revelação ................ 93

3.2.1 Advento, Êxodo e Encontro ................................................................. 96

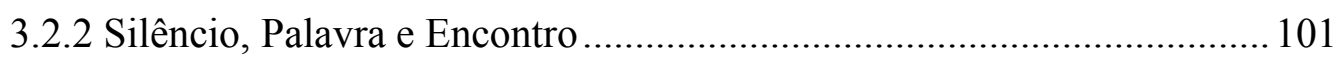

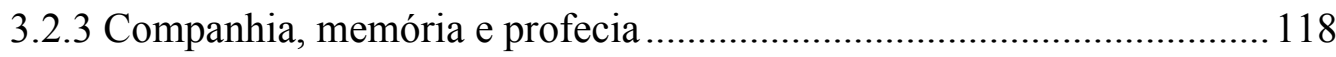

3.3 Trindade como evento de salvação ......................................................... 122

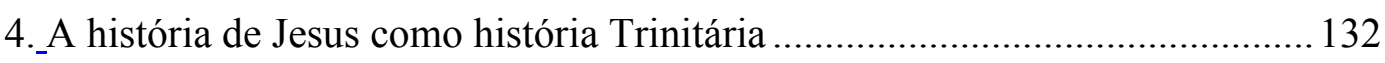

4.1 Consciência e liberdade - a humaníssima história de Jesus ...................... 132

4.1.1 A história da consciência de Jesus e seu aspecto revelador .................... 134

4.1.2 Jesus de Nazaré, o homem livre........................................................... 142

4.2 O escândalo da cruz: a história da entrega de Deus.................................. 147

4.2.1 História de Jesus: uma história de cruz................................................ 147

4.2.2 História da Cruz: a história do amor de Deus ..................................... 152

4.3 Ressurreição: a revelação de Deus na história contraditória da cruz........ 161 


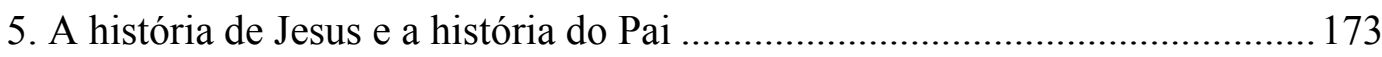

5.1 Os cenários do tempo e a questão do Pai .................................................. 174

5.2 A boa-nova cristã: Jesus é o Filho do Pai ................................................ 179

5.3 O Pai como princípio da história trinitária.............................................. 190

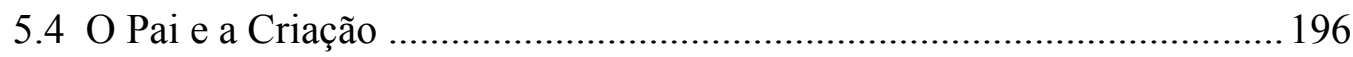

6. A história do Filho, revelação do Espírito .......................................................205

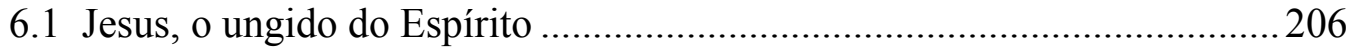

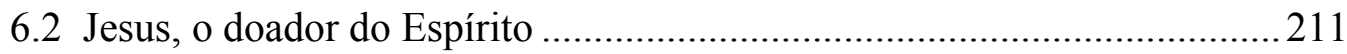

6.3 O Espírito como vínculo do amor.......................................................... 216

6.4 O Espírito e a contemporaneidade de Cristo..............................................2225

7. Cristologia Trinitária e Nova Evangelização..................................................... 238

7.1 O Mistério Trinitário como conteúdo da evangelização...........................2239

7.2 Cristologia Trinitária e conversão pastoral da Igreja ...............................2 251

7.3 Cristologia Trinitária e experiência espiritual.........................................264

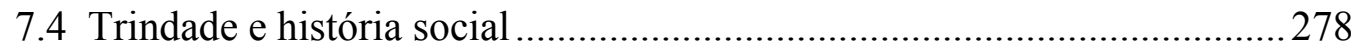

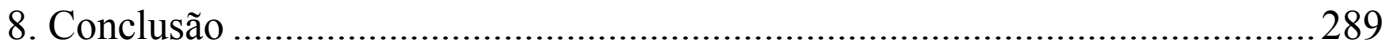

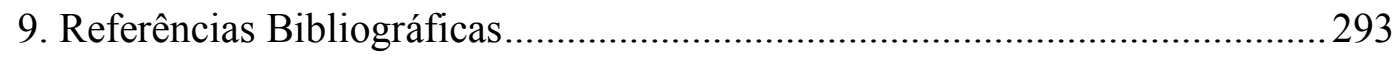




\section{Lista de siglas e abreviaturas}

AA

A enc.

A pred.

A Trin.

Aos Efes.

Aos mag.

Apol.

CCL

ChL

Conf.

Cont. as her.

Cont. Faus.

CT

$D A p$

$D C E$

De car. Crh.

De div. nom.

De duab.

De eccl. Dog.

De Fide

De inc.

De or. dom.

De rev.

De Trin. div.

De Trin. div.

De ver.

De vera Rel.

DH

Dial. com Trif.

DP
Decreto Apostolicam Actuositatem

A encarnação do Verbo

A predestinação dos santos

A Trindade

Carta aos Efésios

Carta aos magnésios

Apologia

Corpus Christianorum.

Exortação Apostólica Christifideles Laici

Confissões

Contra as heresias

Contra Faustum

Exortação Apostólica Catechesi Tradendae,

Documento de Aparecida

Carta Encíclica Deus Caritas Est

De carne Christi

De divinis nominibus

De duabus naturis in Cristo

De ecclesia Dogmatibus

De Fide ad Petrum

De incarnatione

De Oratione Dominica

De revelatione

De Trinitate divina

De Trinitate divina.

De veritate

De vera Religione

Compêndio dos símbolos, definições e declarações de fé e moral

Diálogo com Trifão

Documento de Puebla 
DV

DVi

EA

EG

EN

Ep. Ad Epic.

Epis.

FR

GS

Joan. Evan.

LG

Luc.

$M D$

$M S$

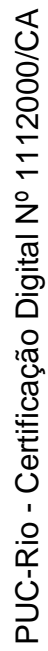

NMI

Ora. Cat. Mag.

Orat.

$P G$

$P L$

$\mathrm{SCh}$

Ser.

Suma Teo.

Sym. Nic.

TCA

Trat. sob.ora.

$U R$
Constituição Dogmática Dei Verbum

Encíclica Dominum et Vivificantem

Exortação Apostólica Pós-Sinodal Ecclesia in Asia

Exortação Apostólica Evangelii Gaudium,

Exortação Apostólica Evangelii Nuntiandi

Epistula ad Epictetum

Epistola

Carta encíclica Fides et Ratio

Constituição Pastoral Gaudium et Spes

Joannis evangelium

Constituição Dogmática Lumen gentium

Lucam

Mulieris dignitatem

Mysterium Salutis

Carta Apostólica Novo Milênio Ineunte

Oratio Catechetica Magna

Oratio

Patrologia Graega

Patrologia Latina

Sources Chrétiennes

Sermo

Suma teológica

Symbolum Nicaenum

Teologia - Cristologia - Antropologia

Tratado sobre a oração

Decreto Unitatis redintegratio 
A essência do Deus vivo é o seu amor em eterno movimento de exodo de si, como Amor amante; de acolhida de si, como amor amado; de regresso a si e de infinita abertura ao outro na liberdade, como Espírito do Amor Trinitário. A essência do Deus cristão é o amor no seu processo eterno, é a história trinitária do amor, é a Trindade como história eterna de amor, que suscita, assume e perpassa a história do mundo, objeto do seu puro amor. O evento pascal não revela de outro modo a essência divina a não ser como evento eterno do amor entre os Três e do seu amor por nós.

Bruno Forte. A essência do Cristianismo 